\title{
PERFORMANCE ENHANCEMENT IN L-BAND EDFA THROUGH DUAL STAGE TECHNIQUE
}

\author{
S. W. Harun and H. Ahmad \\ Department of Physics, Faculty of Science, University Malaya, 50603 Kuala Lumpur \\ E-mail:wadi72@yahoo.com
}

\begin{abstract}
An experiment on gain enhancement in the long wavelength band erbium doped fiber amplifier (L-band EDFA) is demonstrated. It uses a dual stage technique with dual forward pumping scheme. Compared to a conventional single stage amplifier, the small signal gain for $1580 \mathrm{~nm}$ signal can be improved by $5.5 \mathrm{~dB}$ without paying much noise figure penalty. The corresponding noise figure penalty was $0.3 \mathrm{~dB}$ due to the insertion loss of the optical isolator. The optimum pump power ratio for the first pump is experimentally determined to be $33 \%$. The maximum gain improvement of $8.3 \mathrm{~dB}$ was obtained at a signal wavelength of $1568 \mathrm{~nm}$ while signal and total pump powers were fixed at $-30 \mathrm{dBm}$ and $92 \mathrm{~mW}$, respectively. The employment of dual stage amplifier system seems to play an important role in the development of practical L-band EDFA from the perspective of economical usage of pump power.
\end{abstract}

Key Words: erbium doped fibre; optical amplifier; L-band EDFA; dual stage EDFA; amplified spontaneous emission

\section{INTRODUCTION}

Ultra-wideband erbium-doped fiber amplifier (EDFA) now represents one of the promising future network elements, for the ever-increasing high capacity wavelength division multiplexed (WDM) system application [1]. Among many attempts suggested so far, the silica based EDFAs in parallel configuration (C-band: 1530 1560nm plus L-band: $1570 \sim 1610 \mathrm{~nm}$ ) [2-3] have been considered to be the most immediate viable candidate for real system applications, due to the maturity of the supporting technologies. There has been a lack of research effort on L-band EDFA compared to C-band EDFA. The L-band require longer erbium-doped fiber (EDF) lengths to obtain the same gain as a conventional band (C-band) EDFA due to its operating wavelengths are very far from the emission peak of silica-based EDF at $1531 \mathrm{~nm}$. Therefore, many researches for L-band focused on the efficiency improvement, to relax the need for higher pump power compared to C-band EDFA. 


\section{Letter to the Editor}

One of the approaches to power conversion efficiency in L-band EDFA is to recycle a unwanted backward ASE as a secondary pump source to pump an under-pumped EDF section [4]. Other approaches are C-band injection seeding [5] and using a double pass technique [6]. In this letter, two stages L-band EDFA is proposed to improve the gain using optical isolator to split the EDF into two segments. In this amplifier, both segments are pumped separately using forward pumping scheme and the optical isolator is inserted between the first and second stages to eliminate any backward propagating amplified spontaneous emission (ASE).

\section{EXPERIMENTAL SET UP}

The experimental set up is shown in Fig. 1. Figure 1(a) shows a single stage amplifier configuration. Figure 1(b) shows a configuration of the proposed dual stages L-band EDFA, in which an optical isolator splits the EDF 1 into two segments of EDF 2 and EDF 3. EDF with an erbium the peak absorption of $5.6 \mathrm{~dB} / \mathrm{m}$ at the $1531 \mathrm{~nm}$ was used for both configurations. EDF 1 was $50 \mathrm{~m}$ long and it was split into $20 \mathrm{~m}$ for EDF 2 and $30 \mathrm{~m}$ for EDF 3. EDF 1, EDF 2 and EDF 3 are pumped by 980nm laser diode at $92 \mathrm{~mW}, 35 \mathrm{~mW}$ and $57 \mathrm{~mW}$, respectively using forward pumping scheme. The gain and noise figure for the proposed two stages amplifier are measured using optical spectrum analyzer (OSA) and are compared with the single stage amplifier.

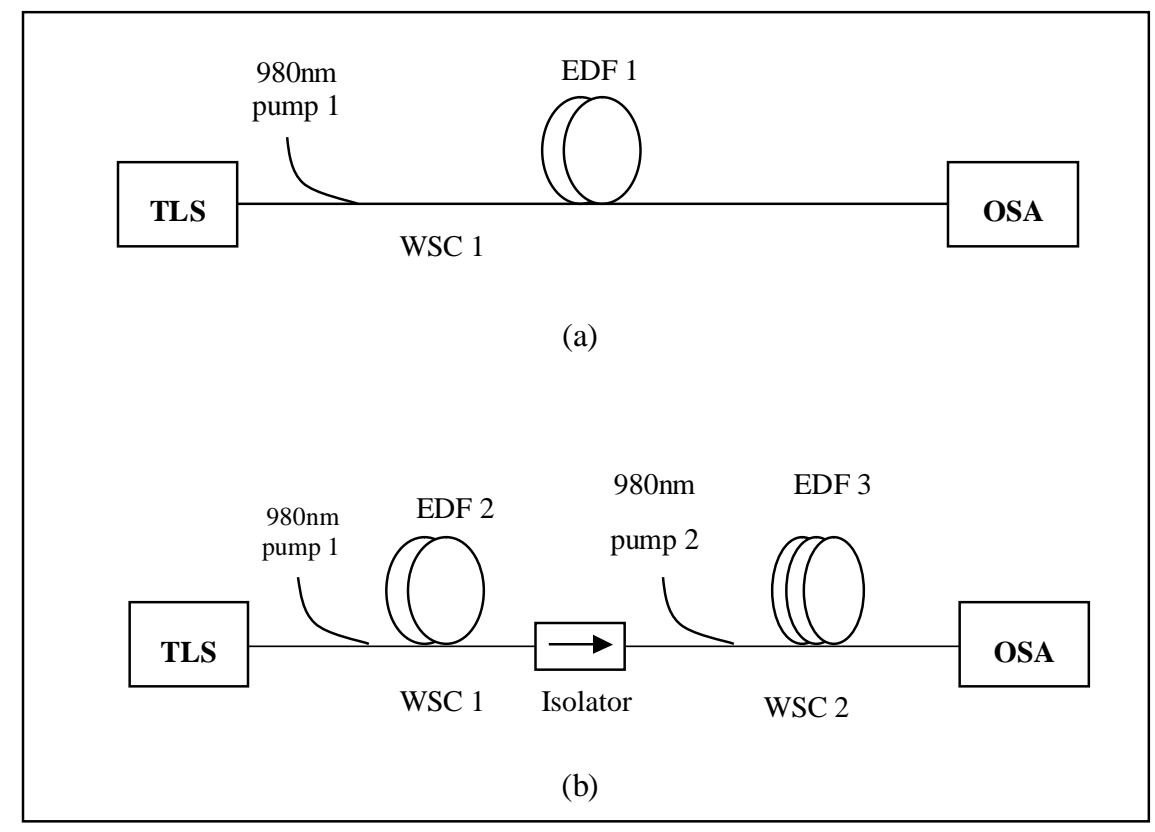

Fig. 1: Configuration of the L-band EDFA (a) single stage (b) dual stage 


\section{Letter to the Editor}

\section{RESULT AND DISCUSSION}

Figure 2 depicts the ASE spectra of both single stage and dual stage amplifiers with a total pump power of $92 \mathrm{~mW}$ where the thin line represents the ASE spectrum of the proposed dual stages amplifier. As seen, the spectrum of the proposed amplifier is much higher than the single stage amplifier, represented by the thick line. By splitting the pumping to two positions along the EDF length as a dual stage amplifier, the ASE level is increased due to large forward ASE from first stage that has not been depleted by backward ASE of second stage. The power level of this ASE spectrum is not very high due to insufficient pump powers to generate the ASE. This can be solved by deploying $1480 \mathrm{~nm}$ laser diodes that provide better power conversion efficiencies and consequently higher ASE powers. The pump power of the first stage is fixed at $35 \mathrm{~mW}$ that is $33 \%$ of the total pump power because this is the optimum value as shown in Fig. 3. Fig. 3 also shows the gain and noise figure as a function of the power ratio of pump 1 . The maximum gain is obtained at $33 \%$ before decreasing slowly until the ratio reached $85 \%$. On the other hand the noise figure shows a constant value of $3.2 \mathrm{~dB}$ at pump 1 ratios of $28 \%$ to $85 \%$.

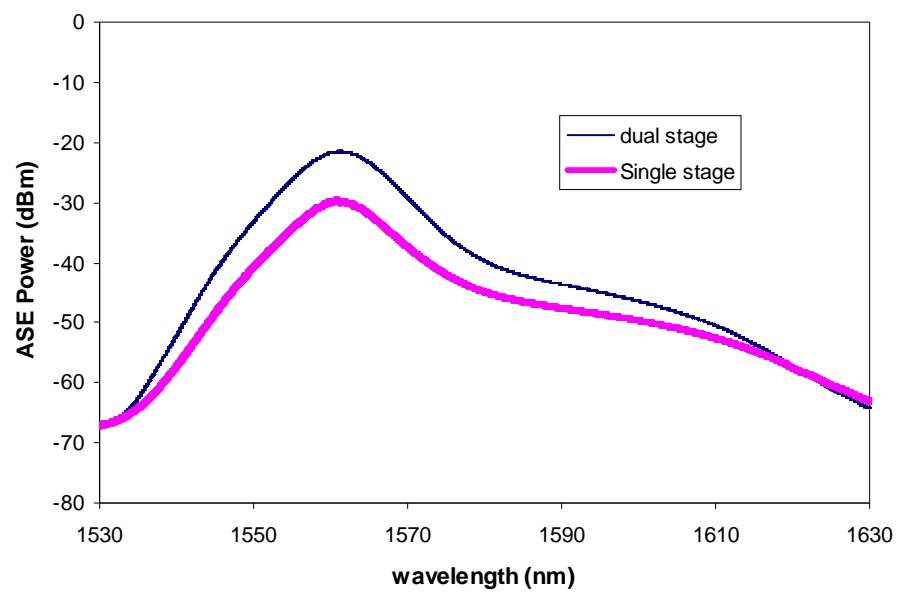

Fig. 2: ASE spectra of the L-band EDFA while the total pump power is fixed at $92 \mathrm{~mW}$. For dual stage amplifier, pump 1 and pump 2 are fixed at $35 \mathrm{~mW}$ and $57 \mathrm{~mW}$, respectively.

The gain and noise figure characteristics of the $1580 \mathrm{~nm}$ signal against input signal power were measured by varying the input signal power from -40 to $0 \mathrm{dBm}$ for both cases as shown in Fig. 4. A gain enhancement of about $5.5 \mathrm{~dB}$ is obtained at small signal levels for the dual stage amplifier compared to single stage amplifier. This is attributed to the dual forward pumping scheme that increased the forward ASE level and thus the amount of energy available for transfer from short to long wavelength also increases. The first stage amplifier works as a pre-amplifier with a relatively high inversion, while the second stage acts as a power amplifier with high pump efficiency. The saturation power of the single and dual stage amplifiers are obtained at $-12 \mathrm{dBm}$ and $-14 \mathrm{dBm}$, respectively. On the other hand, the noise figure of the proposed dual stage amplifier is slightly higher by $0.3 \mathrm{~dB}$ compared to the single stage amplifier for all input signal powers. This noise figure degradation is caused by the inserted component loss. The optical isolator is used to separate the EDF into two 


\section{Letter to the Editor}

sections to prevent the backward ASE from entering the first stage section and degrades the noise figure terribly.

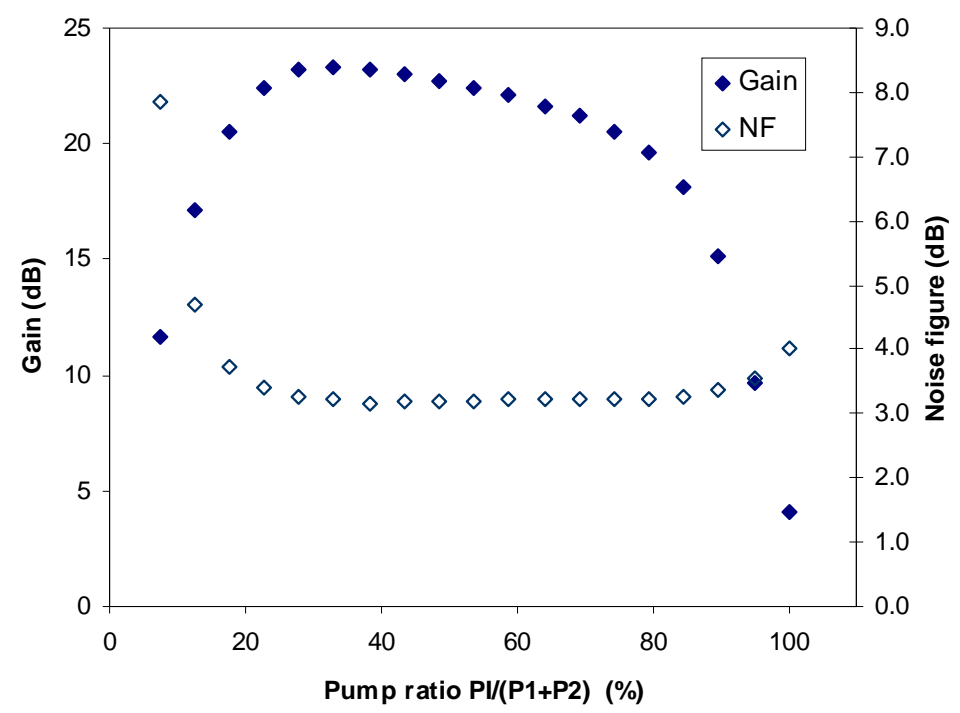

Fig. 3: Gain (closed) and noise figure (clear) as a function of power ratio of pump 1.

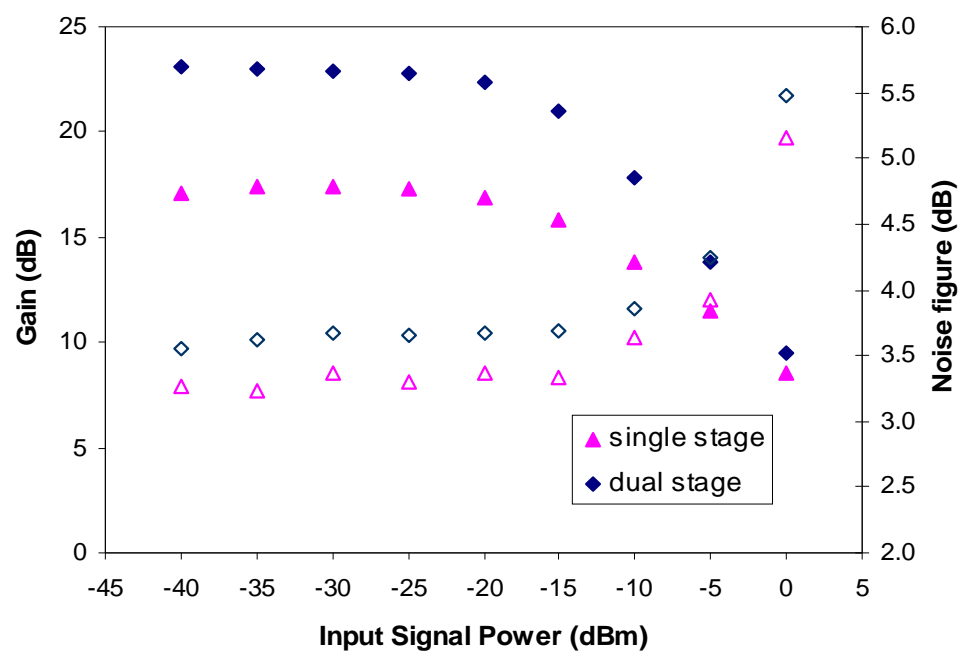

Fig. 4: Gain (closed) and noise figure (clear) as a function of input signal power.

Fig. 5 shows the gain and noise figure spectra for an input signal power of $-30 \mathrm{dBm}$ and total pump power of $92 \mathrm{~mW}$. As seen, the gain of the dual stage amplifier is higher compared to the single stage amplifier especially at shorter wavelengths. This improvement is obtained by amplifying and employing the forward ASE from the first stage to the second stage. The first 10 15 meters of the forward-pumped EDF 


\section{Letter to the Editor}

experiences a very high pump power with correspondingly high population inversion rates in the $\mathrm{C}$-band in both the forward and backward directions. However, insertion of the isolator blocks the backward ASE from the second stage, which has a higher pump power allocation. Suppression of this high power backward ASE, enables builtup of forward ASE in the first stage since there is no other mechanism to deplete the inversion. This results in a very high power forward ASE which can be used to transfer from the higher energy C-bands to the lower energy L-band wavelengths. It also can be seen in Fig. 5 that the maximum gain enhancement value of $8.3 \mathrm{~dB}$ is obtained in the dual stage amplifier compared with the conventional single stage amplifier at wavelengths of $1568 \mathrm{~nm}$. The corresponding noise figure penalty is $0.5 \mathrm{~dB}$. The noise figure penalties were obtained especially at longer wavelengths due to the same reason as explained above.

Fig. 5: Gain (closed) and noise figure (clear) as a function of input signal wavelength.

\section{CONCLUSIONS}

An L-band EDFA with improved gain characteristic, which uses dual forward pumping scheme, has been proposed and demonstrated. The amplifier has improved the small signal gain for $1580 \mathrm{~nm}$ signal by $5.5 \mathrm{~dB}$ at the expense of $0.3 \mathrm{~dB}$ noise figure penalty compared to a conventional single stage amplifier. The noise figure penalty is due to the insertion loss of the optical isolator. The optimum pump power ratio for the first pump is experimentally determined to be $33 \%$. A maximum gain improvement of $8.3 \mathrm{~dB}$ was obtained at a signal wavelength of $1568 \mathrm{~nm}$ while signal and total pump powers were fixed at $-30 \mathrm{dBm}$ and $92 \mathrm{~mW}$, respectively. These results show that the employment of dual stage amplifier system will play an important role in the development of practical L-band EDFA from the perspective of economical usage of pump power. 


\section{Letter to the Editor}

\section{ACKNOWLEDGEMENTS}

One of the authors (S. W. Harun) acknowledges the support of a National Science Fellowship (NSF), MOSTE.

\section{REFERENCES}

[1] A. K. Srivastave, "Wide bandwidth high capacity systems," Opt. Fiber Comm. Conf. 1999, and the International Conf. on Integrated Optics and Opt. Fiber Comm. OFC/IOOC '99. Technical Digest, pp. 59-60, 1999.

[2] M. Yamada, H. Ono, T. Kanamori, S. Sudo and Y. Ohishi, "Broadband and gainflattened amplifier composed of a $1.55 \mu \mathrm{m}$-band and a $1.58 \mu \mathrm{m}$-band $\mathrm{Er}^{3+}$-doped fiber amplifier in a parallel configuration," Electron. Lett., 33, 710-711, 1997.

[3] Y. Sun, J. W. Sulhoff, A. K. Srivastava, J. L. Zyskind, T. A. Strasser, J. R. Pedrazzani, C. Wolf, J. Zhou, J. B. Judkins, R. P. Espindola and A. M. Vengsarkar, "80nm ultrawideband erbium-doped silica fiber amplifier," Electron. Lett., vol. 33, pp. 1965-1967, 1997.

[4] J. Lee, U.-C, Ryu, S. J. Ahn, and N. Park, "Enhancement of power conversion efficiency for a L-band EDFA with a secondary pumping effect in the unpumped EDF section," IEEE Photon. Technol. Lett., 11, 42-44, 1999.

[5] M. A. Mahdi, F. R. Mohamd Adikan, P. Poopalan, S. Selvakennedy, W. Y. Chan and H. Ahmad, "Long wavelength EDFA enhancement through 1550nm band signal injection," Opt. Comm., 176, pp. 125-129, 2000..

[6] S. W. Harun, P. Poopalan and H. Ahmad, "Gain enhancement in L-band EDFA through double pass technique," IEEE Photon. Technol. Lett, 14, pp. 296-298, 2002.

\section{BIOGRAPHY}

Sulaiman Wadi Harun received his B. Eng in electrical and electronic system engineering from Nagaoka University of Technology, Japan in 1996. Currently he is studying for his Ph.D. in Department of Physics, University of Malaya.

Harith Ahmad is a professor at Physic department, Faculty of Science, University of Malaya. He obtained his Ph.D from University of Wales (U.K) in Laser Technology in 1983 and has been involved in laser related research the past 18 years. He has numerous research papers published both local and international journals. 